\title{
A Diet Enriched in Docosahexanoic Acid Exacerbates Brain Parenchymal Extravasation of Apo B Lipoproteins Induced by Chronic Ingestion of Saturated Fats
}

\author{
Menuka M. Pallebage-Gamarallage, ${ }^{1,2}$ Virginie Lam,, ${ }^{1,2}$ Ryusuke Takechi,, \\ Susan Galloway, ${ }^{1,2}$ and John C. L. Mamo',2 \\ ${ }^{1}$ Curtin Health Innovation Research Institute, Curtin University of Technology, Perth, Western Australia 6845, Australia \\ ${ }^{2}$ Centre for Metabolic Fitness, Australian Technology Network Universities, Perth, Western Australia 6845, Australia \\ Correspondence should be addressed to John C. L. Mamo, j.mamo@curtin.edu.au
}

Received 27 May 2011; Revised 4 August 2011; Accepted 26 August 2011

Academic Editor: Spencer D. Proctor

Copyright (C) 2012 Menuka M. Pallebage-Gamarallage et al. This is an open access article distributed under the Creative Commons Attribution License, which permits unrestricted use, distribution, and reproduction in any medium, provided the original work is properly cited.

\begin{abstract}
Chronic ingestion of saturated fatty acids (SFAs) was previously shown to compromise blood-brain barrier integrity, leading to brain parenchymal extravasation of apolipoprotein B (apo B) lipoproteins enriched in amyloid beta. In contrast, diets enriched in mono- or polyunsaturated (PUFA) oils had no detrimental effect. Rather, $\mathrm{n} 3$ and $\mathrm{n} 6$ oils generally confer protection via suppression of inflammation. This study investigated in wild-type mice if a PUFA diet enriched in docosahexanoic acid (DHA) restored bloodbrain barrier integrity and attenuated parenchymal apo B abundance induced by chronic ingestion of SFA. Cerebrovascular leakage of apo B was quantitated utilising immunofluorescent staining. The plasma concentration of brain-derived S100 $\beta$ was measured as a marker of cerebrovascular inflammation. In mice fed SFA for 3 months, provision thereafter of a DHA-enriched diet exacerbated parenchymal apo B retention, concomitant with a significant increase in plasma cholesterol. In contrast, provision of a low-fat diet following chronic SFA feeding had no effect on SFA-induced parenchymal apo B. The findings suggest that in a heightened state of cerebrovascular inflammation, the provision of unsaturated fatty acids may be detrimental, possibly as a consequence of a greater susceptibility for oxidation.
\end{abstract}

\section{Introduction}

Accumulating evidence supports the hypothesis that dietary behaviour and in particular ingestion of fats contribute to Alzheimer's disease (AD) onset and progression. The work in [1] reported that the prevalence of sporadic and late-onset $\mathrm{AD}$ in $>65$ years of age subjects correlated with fat intake and was higher in Western countries, compared to Africa or Asia. Population and clinical studies also suggest that regular consumption of saturated fatty acids (SFAs) and trans-fatty acids as well as cholesterol is synergistically and positively associated with increased risk of $\mathrm{AD}[1,2]$ through mechanisms that include dyslipidemia, endothelial dysfunction, inflammation, and oxidative stress. In contrast, populations with greater consumption of fats as poly- or mono-unsaturated oils (PUFA and MUFA, resp.) have lower prevalence of $\mathrm{AD}$ and vascular based dementias [1-4], probably as a consequence of lower levels of systemic inflammation [5-7].

In $\mathrm{AD}$, chronic inflammation leading to neuronal loss appears to be primarily associated with cerebrovascular and brain parenchymal deposits of amyloid beta $(\mathrm{A} \beta)$ [8]. Derived from the amyloid precursor protein, $A \beta$ is the predominant component of "amyloid" (or senile) plaques [9, 10]. Key triggers of cerebrovascular amyloidosis are thought to include enhanced proteolytic processing of the precursor protein on the plasma membrane of neuronal cells [1113], a phenomenon more common in early-onset AD. In addition, fibrillar formation of $A \beta$ and deposition upon extracellular matrices may also reflect decreased degradation and efflux by epithelial cells of the choroid plexus [14, 15]. Alternatively, cerebral parenchymal $\mathrm{A} \beta$ load may be exacerbated if cerebrovascular integrity is compromised and 
blood-to-brain delivery of peripheral $A \beta$ is increased [16, 17]. Moreover, the latter typically results in the activation of astro-glial cells and oxidation of proteins and lipids $[18,19]$.

Significant plasma $A \beta$ is found associated with triglyceride-rich lipoproteins (TRLs) and cell culture and immunohistochemical studies confirm secretion of $A \beta$ as a TRL from hepatocytes and absorptive epithelial cells of the small intestine [20-22]. In humans there is a transient increase in plasma $\mathrm{A} \beta$ concentration, following the consumption of a mixed lipid meal and kinetic studies in vivo showing that $A \beta$ serves as a regulating apolipoprotein of TRLs [23]. However, several lines of evidence suggest that persistent disturbances in the TRL-A $\beta$ pathway may contribute to $\mathrm{AD}$ risk. In three strains of amyloid transgenic mice, secretion into plasma of TRL-A $\beta$ was strongly associated with onset and progression of amyloidosis [24]. Moreover, significant cerebrovascular disturbances were reported preceding plaque formation in amyloid transgenic mice [25]. Consistent with the concept of disease induction in response to exaggerated exposure, subjects with $\mathrm{AD}$ were reported to have significantly elevated plasma TRL-A $\beta$ concomitant with evidence postprandial dyslipidaemia [26]. Moreover, in human cadaver and in transgenic-amyloid mice brain specimens, significant apolipoprotein B (apo B) immunoreactivity colocalized with early diffused amyloid plaque [27, 28].

To explore directly the hypothesis of a dietary fat modulation of TRL-A $\beta$ and cerebrovascular integrity axis, wild-type (WT) mice were fed diets enriched in either SFA, MUFA, or PUFAs [28]. Within 12 weeks of dietary intervention, mice maintained on the SFA diet showed substantial parenchymal extravasation of plasma proteins including apo B lipoproteins enriched with $A \beta$. The endothelial tight junction protein occludin was substantially attenuated in SFA-fed mice concomitant with substantially increased enterocytic abundance of $A \beta[28,29]$. In contrast, mice maintained on either the MUFA or PUFA diets had no cerebrovascular aberrations and penetration of plasma proteins in these two groups was comparable to low-fat- (LF-) fed controls.

The potential cytotoxic properties of SFA are established and the principal mechanisms include mitochondrial respiratory burst resulting in oxidative stress and endoplasmic reticulum dysfunction [30]. Polyunsaturates on the other hand and in particular docosahexanoic acid (DHA) generally antagonise the effects of SFA and are purported to confer cytoprotection because of potent anti-inflammatory effects [5, 31-33]. However, unsaturated fatty acids such as DHA are highly susceptible to lipid peroxidation and if inflammation is already established, then oxidative damage may be paradoxically amplified with the provision of unsaturated fatty acids such as DHA. To explore the hypothesis that polyunsaturated fatty acids confer benefit and not risk in a cerebrovascular proinflammatory state, we explored parenchymal extravasation of apo B lipoproteins in WT mice initially maintained on an SFA-enriched diet for 3 months, followed by randomization to either an LF- or a PUFA-enriched diet for 2 months.

\section{Methods}

2.1. Animals and Diet Conditions. The animal housing, handling, and experimental procedures described for this study were approved by the Curtin University Animal Experimentation and Ethics Committee. Six-week-old female WT mice $(\mathrm{C} 57 \mathrm{BL} / 6 \mathrm{~J})$ were housed in groups and randomized into their respective diets ( $n=6$ mice per group). All mice were maintained on a $12 \mathrm{~h}$ light and dark cycle room, at $22^{\circ} \mathrm{C}$ and with free access to water and food.

Mice were fed an SFA diet (SF07-050, Glen Forrest Stockfeeders, Glen Forrest, Western Australia) for 3 months and then randomised to receive either an LF (AIN-93M, Glen Forrest Stockfeeders), PUFA-enriched (SF07-049, Glen Forrest Stockfeeders), or maintained on SFA for a further 2 months. Fatty acid composition for each diet is shown in Table 1. Digestible energy for the SFA diet was $18.8 \mathrm{MJ} / \mathrm{kg}$ and contained palmitic $(16: 0)$ and stearic $(18: 0)$ as the principle saturated fats $(13 \%, \mathrm{w} / \mathrm{w})$. The LF diet contained $4 \%(\mathrm{w} / \mathrm{w})$ as total fat and $15.1 \mathrm{MJ} / \mathrm{kg}$ of digestible energy and only $<1 \%$ of total digestible energy from lipids. The PUFA diet contained $8.22 \%(\mathrm{w} / \mathrm{w})$ of DHA and $2.00 \%(\mathrm{w} / \mathrm{w})$ eicosapentaenoic acid (EPA) sourced from NUMEGA fish oil. The diet generated $18.8 \mathrm{MJ} / \mathrm{kg}$ of digestible energy where $40 \%$ of energy derived from lipids. All diets had sufficient essential fatty acids.

2.2. Tissue Collection and Sample Preparation. Blood and brain samples were collected as previously described by Takechi et al. [28]. Mice were anaesthetised with pentobarbitone $(45 \mathrm{mg} / \mathrm{kg}$ i.p.), and exsanguinated by cardiac puncture. Blood was collected into K-2 EDTA tubes and stored in ice. Plasma was separated by short speed centrifugation at $4^{\circ} \mathrm{C}$ and stored at $-80^{\circ} \mathrm{C}$.

Brain tissues were carefully isolated, washed with chilled phosphate buffer saline (PBS, $\mathrm{pH}$ 7.4), right hemispheres were separated, and fixed in $4 \%$ paraformaldehyde for $24 \mathrm{~h}$. The tissues were then cryoprotected with $20 \%$ sucrose solution at $4^{\circ} \mathrm{C}$ for $72 \mathrm{~h}$, frozen in isopentane with dry ice and stored at $-80^{\circ} \mathrm{C}$. For histology and fluorescence microscopy, serial cryosections of $18 \mu \mathrm{m}$ were cut from the right cerebral hemispheres for each mouse and mounted on Polysine slides (LabServ, Australia).

2.3. Cerebral Apo B Immunofluorescence. Cerebrovascular leakage of apo B was detected as previously described [28]. Brain cryosections $(18 \mu \mathrm{m})$ were air-dried for $30 \mathrm{~min}$, rehydrated with $\mathrm{PBS}$ and incubated in blocking serum ( $10 \%$ goat serum) for $30 \mathrm{~min}$ prior to the application of the antibodies. Cerebral apo B was detected by overnight incubation with the primary antibody polyclonal rabbit antiapo B (ab20737, Abcam, Cambridge, UK) at 1:500 dilution, at $4^{\circ} \mathrm{C}$. Postovernight incubation and washing with PBS, primary antibody was labelled at room temperature with the secondary goat anti-rabbit IgG-Alexa 488 fluorochrome conjugate (A-11034, Invitrogen) for $2 \mathrm{~h}$. The sections were then washed with PBS and the nuclei were counterstained with DAPI $(1: 1000)$ for $5 \mathrm{~min}$ at room temperature. Thereafter, the stained sections were mounted with antifade mounting 
TABle 1: Dietary composition.

\begin{tabular}{|c|c|c|c|}
\hline & SFA diet & LF diet & DHA diet \\
\hline \multicolumn{4}{|l|}{ Calculated nutritional parameters (\%) } \\
\hline Protein & 13.6 & 13.6 & 13.6 \\
\hline Total fat & 20.3 & 4 & 20.3 \\
\hline Crude fibre & 4.7 & 4.7 & 4.7 \\
\hline Acid detergent Fibre & 4.7 & 4.7 & 4.7 \\
\hline Digestible energy & $18.8 \mathrm{MJ} / \mathrm{kg}$ & $15.1 \mathrm{MJ} / \mathrm{kg}$ & $18.8 \mathrm{MJ} / \mathrm{kg}$ \\
\hline \% Digestible energy from lipids & 40 & $\mathrm{n} / \mathrm{a}$ & 40 \\
\hline$\%$ Digestible energy from protein & 15 & $\mathrm{n} / \mathrm{a}$ & 15 \\
\hline \multicolumn{4}{|l|}{ Calculated fat composition (\%) } \\
\hline Myristic acid 14:0 & 0.05 & Trace & 0.54 \\
\hline Pentadecanoic acid 15:0 & 0.01 & $\mathrm{n} / \mathrm{a}$ & 0.16 \\
\hline Palmitic acid 16:0 & 5.16 & 0.2 & 3.26 \\
\hline Megaric acid 17:0 & 0.05 & $\mathrm{n} / \mathrm{a}$ & 0.18 \\
\hline Stearic acid 18:0 & 7.31 & 0.1 & 0.92 \\
\hline Arachidic acid 20:0 & 0.24 & $\mathrm{n} / \mathrm{a}$ & 0.06 \\
\hline Behenic acid 22:0 & 0.04 & $\mathrm{n} / \mathrm{a}$ & 0.05 \\
\hline Tetracosanoic acid 24:0 & 0.03 & $\mathrm{n} / \mathrm{a}$ & 0.05 \\
\hline Palmitoleic acid 16:1 & 0.05 & Trace & 0.66 \\
\hline Heptadecenoic acid 17:1 & 0.01 & $\mathrm{n} / \mathrm{a}$ & 0.10 \\
\hline Oleic acid 18:1 n9 & 6.62 & 2.4 & 2.25 \\
\hline Gadoleic acid 20:1 & 0.01 & $\mathrm{n} / \mathrm{a}$ & 0.18 \\
\hline Lenoleic acid 18:2 n6 & 0.67 & 0.8 & 0.23 \\
\hline a Linolenic acid 18:3 n3 & 0.05 & 0.4 & 0.09 \\
\hline g Linolenic acid 18:3 n6 & Not detected & $\mathrm{n} / \mathrm{a}$ & 0.08 \\
\hline Arachadonic acid 20:4 n6 & Not detected & Trace & 0.46 \\
\hline EPA 20:5 n3 & Not detected & Trace & 2.00 \\
\hline DHA 22:6 n3 & Not detected & Trace & 8.22 \\
\hline
\end{tabular}

The total fatty acid composition of SFA, LF, and DHA diets. Vitamin and mineral contents were balanced in all diets.

medium. Primary antibody was replaced with buffer or an irrelevant serum for negative control tissues.

2.4. Quantitative Immunofluorescent Imaging and Analysis. Digital images for photomicroscopy were acquired through AxioCam HRm camera (Carl Zeiss, Germany) with an AxioVert $200 \mathrm{M}$ inverted microscope by Zeiss (Germany) at $\times 200$ magnification (Plan Neofluar $\times 20$ objective, 1.3 numerical aperture). Three-dimensional (3D) images were captured through ApoTome optical sectioning methodology (Carl Zeiss). Each 3D image consisted of 6-10 twodimensional (2D) images and the distance between Z-stack slices was $1.225 \mu \mathrm{m}$ optimised by Nyquist. A minimum of nine $3 \mathrm{D}$ images were randomly captured per mouse, which include 5 images within the cortex (CTX) and 2 images each from brainstem (BS) and hippocampal formation (HPF).

Cerebrovascular leakage of plasma protein apo B was quantified within the CTX excluding the hippocampus, BS, and HPF. The pixel intensity of the protein of interest for each 3D image was calculated utilising the automated optical intensity measurement tool in Volocity (Software version 5.5, Perkin Elmer, Melbourne, Australia) and expressed as per unit volume. The investigator was blinded during imaging and quantitation.
2.5. Plasma Cholesterol, Triglyceride, and NEFA. Plasma cholesterol and triglycerides were determined in duplicate by enzymatic assays (Randox Laboratories LTD, UK). Nonesterified fatty acids (NEFAs) were determined with NEFAC (ASC-ACOD method, Wako Pure Chemical Industries, Osaka, Japan).

2.6. Plasma S100 $\beta$ Analysis. Plasma $\mathrm{S} 100 \beta$ is used as a marker of cerebrovascular inflammation and was measured using ELISA kits according to manufacturers' instructions (CosmoBio, Tokyo, Japan). Plasma S100 $\beta$ was measured with $30 \mu \mathrm{L}$ of plasma sample or standard and incubated in precoated microtitre well plates at $4^{\circ} \mathrm{C}$ overnight. Plates were then incubated with biotinylated secondary antibody and Streptavidin-HRP for $2 \mathrm{~h}$, each. Colour generated with substrate and optical density determined at $492 \mathrm{~nm}$. After adjusting for sample dilution, final concentrations of plasma S100 $\beta$ were extrapolated from standard curve.

2.7. Statistical Analysis. This study utilised $n=6$ mice per group and minimum of nine $3 \mathrm{D}$ images were captured per mouse for detection of apo B leakage. Each 3D image was constructed by stacking of sequential 2D images, therefore generating 324-540 two-dimensional images per group. All 
TABLE 2: Effects of various feeding regimens on plasma lipids in wild-type (C57BL/6J) mice.

\begin{tabular}{lclc}
\hline & SFA $5 \mathrm{~m}$ & + LF $2 \mathrm{~m}$ & + DHA $2 \mathrm{~m}$ \\
\hline TG $(\mathrm{mM})$ & $0.39 \pm 0.04$ & $0.54 \pm 0.03^{*}$ & $0.43 \pm 0.04$ \\
TC $(\mathrm{mM})$ & $1.45 \pm 0.23$ & $1.69 \pm 0.17$ & $3.11 \pm 0.12^{* *}$ \\
NEFA $(\mathrm{mEq} / \mathrm{L})$ & $0.42 \pm 0.03$ & $0.45 \pm 0.03$ & $0.53 \pm 0.05$ \\
Body weight & & & \\
$\quad$ Final & $25.65 \pm 0.64$ & $23.72 \pm 0.96$ & $20.21 \pm 0.50^{* *}$ \\
$\quad$ Weight gain & $8.41 \pm 0.51$ & $5.7 \pm 1.12$ & $3.3 \pm 0.51^{* *}$ \\
\hline
\end{tabular}

Plasma total cholesterol (TC), triglycerides (TGs), and non-esterified fatty acids (NEFAs) were measured at the end of the feeding regimen in mice fed saturated fats (SFA $5 \mathrm{~m}$ ) and SFA-fed mice switched to an LF (+LF $2 \mathrm{~m}$ ) and DHA diet (+DHA $2 \mathrm{~m}$ ). Final body weight and weight gain were also calculated. Data represented as mean \pm standard error of mean. Means were compared with one-way ANOVA, where $P<0.05$ considered statistically significant $(*)$.

data was analysed by either parametric or nonparametric one-way Analysis of Variance to assess the main effects of LF and DHA on dietary SFA-induced blood-brain barrier (BBB) dysfunction and their two-way interactions. Post-hoc comparison of means was done if the associated main effect or interaction was statistically significant within the Analysis of Variance procedure. $P$ values $<0.05$ were considered statistically significant.

\section{Results}

We confirm previous studies showing significant CTX $>$ BS $>$ HPF extravasation of apo B lipoproteins in WT mice maintained on an SFA diet for a total of 5 months (3 months plus randomization to SFA for an additional 2 months: Figures 1 and 2). Mice randomized to an LF diet following 3 months of SFA feeding had comparable levels of parenchymal apo B lipoprotein abundance to mice maintained on SFA feeding alone (Figures 1 and 2). However, in mice randomized to the DHA-enriched diet following 3 months of SFA feeding, parenchymal apo B abundance was markedly increased (Figures 1 and 2). The cerebrovascular effects of the DHA diet occurred commensurate with a 2-fold increase in plasma cholesterol compared to mice maintained on the SFA diet (Table 2). In contrast, the LF diet had no significant impact on plasma lipid homeostasis. Disturbances in $\mathrm{BBB}$ integrity and function were supported by the findings of substantially increased plasma S100 $\beta$ in the SFA $\rightarrow$ DHA mice compared to SFA alone (Figure 3 ). The protein $\mathrm{S} 100 \beta$ is commonly used as a surrogate marker of brain-toblood leakage. The $S 100 \beta$ is a cytokine produced exclusively by the astrocytes of the central nervous system. Following randomization, differences in food consumption were identified. Mice maintained on SFA or randomized to the LF consumed on average $3 \mathrm{~g} /$ day, whereas consumption of the DHA-enriched diet was reduced to $2 \mathrm{~g} /$ day. The lower caloric intake of mice on the DHA enriched diet resulted in a slower rate of growth following randomization (Table 2).

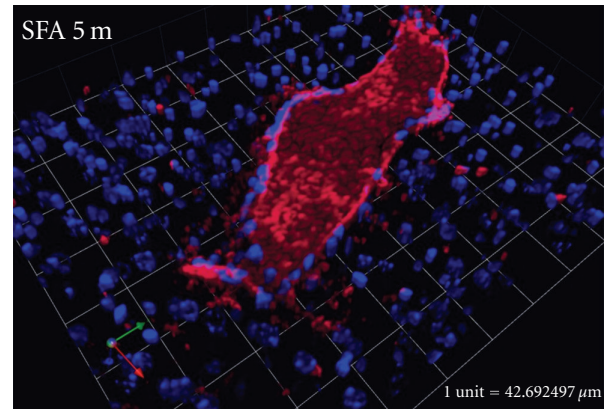

(a)

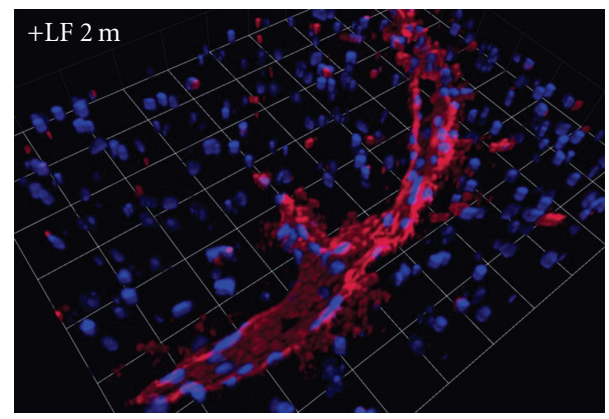

(b)

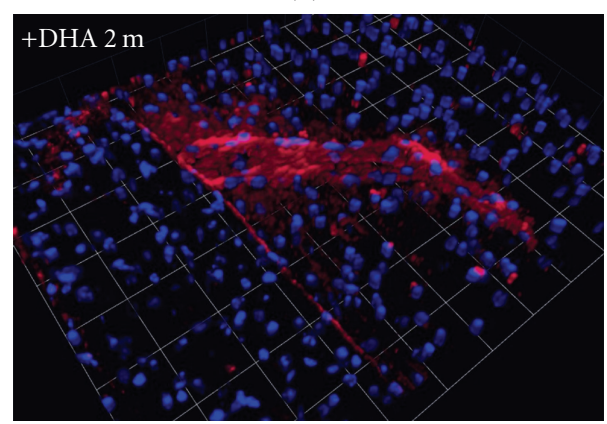

(c)

FIGURE 1: Three-D immunofluorescent staining of cerebral extravasation of apo B. Parenchymal leakage of apo B lipoproteins (red) is observed surrounding the cerebral microvessels. Nuclei are shown in blue. The 3D images are from mice maintained on saturated-fat diet for 5 months (SFA $5 \mathrm{~m}$ ) and SFA fed mice randomised to LF (+LF $2 \mathrm{~m}$ ) and DHA (+DHA $2 \mathrm{~m}$ ) diet for further 2 months. Scale: 1 unit $=42.7 \mu \mathrm{m}$.

\section{Discussion}

This study was designed to explore if provision of a diet enriched in DHA attenuated cerebrovascular dysfunction induced by chronic ingestion of an SFA diet. The primary outcome measure was to determine the abundance of brain parenchymal apo B lipoproteins that transport significant endogenous $\mathrm{A} \beta$. Cerebral capillary vessels normally have tightly apposed endothelial cells that ordinarily prevent transport of plasma proteins and macromolecules [34].

The primary finding of this study showed that provision of a PUFA diet principally enriched in DHA exacerbated brain parenchymal extravasation of apo B lipoproteins that had been initially induced by chronic ingestion of SFA. Previous studies exploring the effect on cerebrovascular integrity 


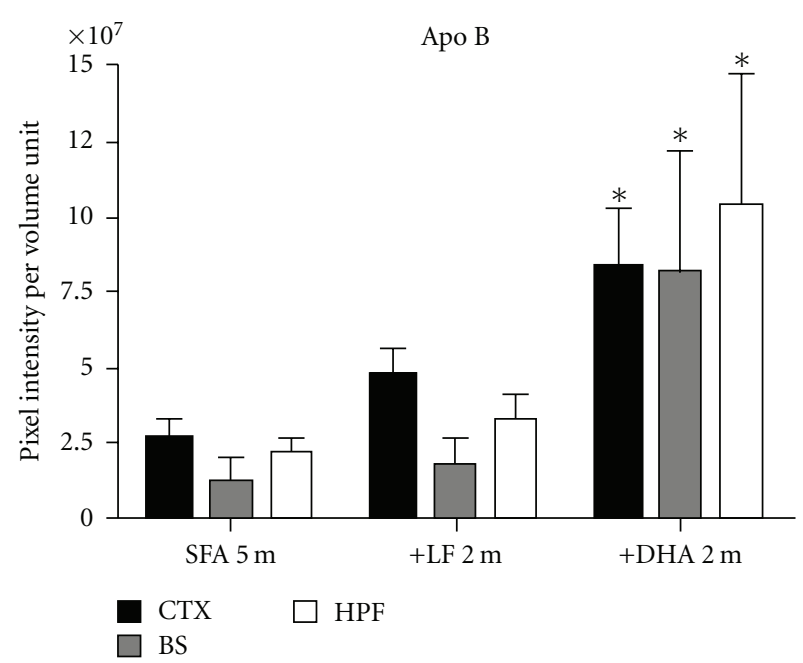

FIgURE 2: Three-dimensional (3D) quantitative analysis of apo B leakage in C57BL/6J mouse brain. Pixel intensity of apo B lipoproteins surrounding the cerebrovasculature was quantitated in $3 \mathrm{D}$ images from mice maintained on saturated-fat diet for 5 months (SFA $5 \mathrm{~m}$ ) and SFA-fed mice randomised to LF (+LF $2 \mathrm{~m}$ ) and DHA (+DHA $2 \mathrm{~m}$ ) diet for further 2 months. The extent of apo B pixel intensity was measured in the cortex (CTX), brain stem (BS), and hippocampal formation (HPF) and expressed as per unit volume. The bars represent mean intensity and standard error of mean, where $P<0.05$ considered statistically significant (* Kruskal Wallis $t$-test). The C57BL/6J mice randomised to DHA diet (+DHA) had elevated apo B intensities in all regions of the brain.

and function by the SFA and PUFA diets described here, as well as an MUFA-enriched diet, showed in C57BL/6J mice that only the SFA diet induced parenchymal accumulation of apo B lipoproteins [28]. Therefore, the paradoxical effects of the PUFA diet are likely to be a consequence of amplification of proinflammatory pathways induced as a consequence of chronic SFA ingestion. Consistent with this concept, SFA-fed mice randomized to an LF diet showed similar parenchymal apo B abundance and plasma $S 100 \beta$ as mice that were maintained on SFA alone.

Several studies have provided evidence of a vasoactive role of $A \beta$, with pathological manifestations prior to $A \beta$ deposition. Exogenous administration of $A \beta$ is vasoconstrictive and vessels treated with $A \beta$ show significant endothelial cell damage with changes in the cell membrane, cytoplasm, nucleus, and other organelles [16]. Takechi et al. [28] suggested that that chronic ingestion of SFA may increase TRL$\mathrm{A} \beta$ secretion and that repeated postprandial excursions may eventually disrupt BBB function. Consistent with this possibility, SFAs were shown to stimulate enterocytic $A \beta$ abundance and released into the circulation associated with postprandial TRL and a similar phenomenon may also occur in liver $[20,35]$. Moreover, diets enriched in SFA reduce high affinity clearance pathways of TRL-remnant lipoproteins and this may contribute to increased postprandial lipaemia and plasma $\mathrm{A} \beta[36,37]$.

In this study, parenchymal apo B abundance did not correlate with plasma triglyceride concentration. Mice fed the DHA-enriched diet had comparable triglycerides to the

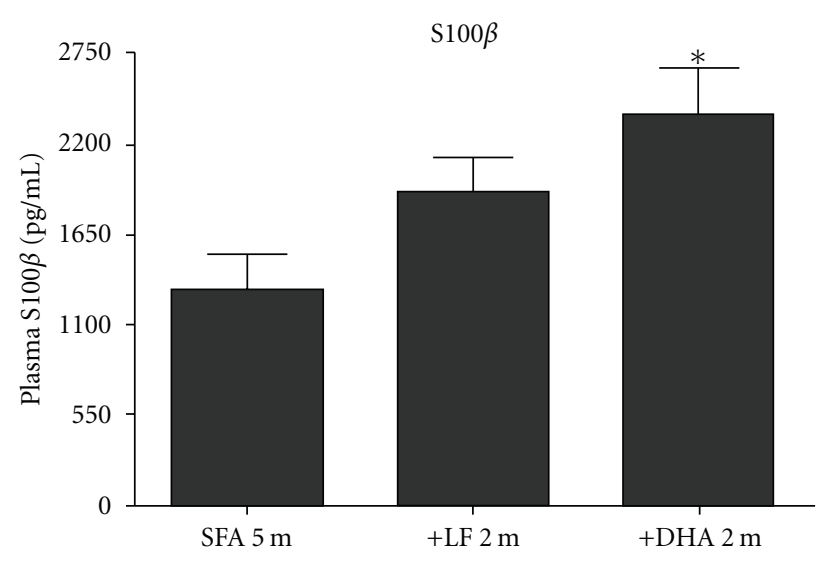

FIGURE 3: Effect of dietary fatty acids on plasma S100 $\beta$ concentration in C57BL/6J mice. The brain abundant protein S100 $\beta$ was measured in plasma as a surrogate marker of BBB leakage. High plasma $S 100 \beta$ concentration in SFA-fed mice correlate with significant $\mathrm{BBB}$ dysfunction. In comparison to SFA $5 \mathrm{~m}$ group, plasma $\mathrm{S} 100 \beta$ was significantly increased in mice switched to the DHA diet (+DHA $2 \mathrm{~m}$ ). The bars represent mean plasma concentration $(\mathrm{pg} / \mathrm{mL})$ and standard error of mean, where $P<0.05$ considered statistically significant (* one-way ANOVA).

SFA group and plasma triglycerides were greatest in SFA mice randomized to LF. Saturated fats often increase plasma NEFA concentration compared to low-fat diets, whereas DHA generally accelerates TRL clearance by facilitating LPLmediated lipolysis $[38,39]$. However, in this study, there was no significant increase in net concentration of plasma NEFA in mice randomized to the DHA diet versus those maintained on SFA alone $(0.53 \pm 0.05$ versus $0.42 \pm 0.03 \mathrm{mEq} / \mathrm{L}$, resp.). Nonetheless, a role of fatty acids in modulating cerebrovascular integrity cannot be ruled out because fatty acid phenotype may be critically important. Many studies suggest significant vascular effects of fatty acids. Human aortic endothelial cells treated with TRL and lipoprotein lipase (LPL) were highly permeable, whilst cells treated with TRL or LPL alone were not [40]. Furthermore, LPL-mediated TRL lipolysis initiated degradation of the tight junction protein $\mathrm{ZO}-1$ and induced an endothelial apoptotic cascade.

The most significant lipid effect of randomization to DHA following chronic ingestion of SFA in this study was a twofold increase in plasma cholesterol compared to the mice maintained on the SFA diet, or mice randomied to the LF diet. A number of animal and clinical studies have shown that DHA-enriched diets can increase plasma cholesterol associated with low- and high-density lipoproteins [41-43]. Hypercholesterolemia has been associated with many vasculature abnormalities including endothelial dysfunction, decreased vascular reactivity, and enhanced expression of adhesion molecules [44, 45]. Cell culture studies suggest several mechanisms by which cholesterol may be pro-inflammatory and some of these appear to be analogous to the effects of dietary SFA. Yao and colleagues reported that excess cholesterol causes endoplasmic reticulum and mitochondrial stress that can lead to apoptosis [46]. Mitochondrial activity or microsomal processing also results in the production 
of oxidized lipids that trigger and exacerbate inflammatory pathways [47].

The anti-inflammatory properties of particularly the $n 3$ and $n 6$ fatty acids have been unequivocally demonstrated in many studies. However, the propensity for PUFA to oxidize may under some circumstances amplify oxidative stress sequelae. Diets enriched in SFA enhance oxidation as a consequence of stimulated mitochondrial function in activated macrophages [46]. Dietary SFA diminish the proper function of the cerebrovascular endothelial cells and are thereafter likely to activate astro-glial cells which encompass cerebral capillary vessels. It's plausible that enhanced interaction of plasma PUFA's in DHA-fed mice with activated inflammatory cells may be a primary mechanism by which the effects of SFA are amplified. Consistent with this possibility, Kuo et al. [48] showed a dose effect of dietary DHA on BBB permeability in mice supplemented with $12 \%$ fish oil for 6 months, versus mice fed $3 \%$ fish oil. Similarly, rats consuming fish oil exhibited increased lipid peroxidation $[49,50]$ and oxidative stress-induced damage of DNA in the absence of dietary antioxidants [51]. In vitro, DHA and EPA enhanced lipid peroxidation and triggered cellular apoptosis $[52,53]$.

\section{Summary}

Chronic ingestion of diets enriched in SFA commonly causes vascular dysfunction, including in capillary vessels of the brain. The effects of SFA could be described as a responseto-injury phenomenon induced by exaggerated exposure to plasma triglyceride, cholesterol, NEFA, or harmful inflammatory products of lipid metabolism, such as lipid peroxides. Many studies support a role of $\mathrm{n} 3$ and $\mathrm{n} 6$ fatty acids in the prevention of vascular, based disorders primarily via suppression of inflammatory cascades. Less clear however are the benefits of polyunsaturated oils in the presence of profound inflammation, because of the propensity to generate lipid peroxidation products.

In an established model of cerebrovascular dysfunction induced by chronic ingestion of an SFA-enriched diet, provision of DHA amplified the harmful effects. Probable mechanisms include hypercholesterolemia and perhaps fatty acidinduced cytotoxicity. The data suggests that introduction of $\mathrm{n} 3 / \mathrm{n} 6$ fatty acids in metabolic conditions that are characterized by heightened systemic inflammation needs to be carefully considered in the context of paradoxical detrimental effects that could occur.

\section{References}

[1] W. B. Grant, "Dietary links to Alzheimer's disease," Alzheimer's Disease Review, vol. 2, pp. 42-55, 1997.

[2] S. Kalmijn, L. J. Launer, A. Ott, J. C. M. Witteman, A. Hofman, and M. M. B. Breteler, "Dietary fat intake and the risk of incident dementia in the Rotterdam study," Annals of Neurology, vol. 42, no. 5, pp. 776-782, 1997.

[3] P. Barberger-Gateau, L. Letenneur, V. Deschamps, K. Pérès, J. F. Dartigues, and S. Renaud, "Fish, meat, and risk of dementia: cohort study," British Medical Journal, vol. 325, no. 7370, pp. 932-933, 2002.
[4] M. C. Morris, D. A. Evans, J. L. Bienias et al., "Dietary fats and the risk of incident Alzheimer disease," Archives of Neurology, vol. 60, no. 2, pp. 194-200, 2003.

[5] L. Ferrucci, A. Cherubini, S. Bandinelli et al., "Relationship of plasma polyunsaturated fatty acids to circulating inflammatory markers," Journal of Clinical Endocrinology and Metabolism, vol. 91, no. 2, pp. 439-446, 2006.

[6] S. C. Dyall, "Amyloid-beta peptide, oxidative stress and inflammation in Alzheimer's disease: potential neuroprotective effects of omega-3 polyunsaturated fatty acids," International Journal of Alzheimer's Disease, vol. 2010, Article ID 274128, 20 pages, 2010.

[7] I. Vedin, T. Cederholm, Y. F. Levi et al., "Effects of docosahexaenoic acid-rich n-3 fatty acid supplementation on cytokine release from blood mononuclear leukocytes: the OmegAD study," American Journal of Clinical Nutrition, vol. 87, no. 6, pp. 1616-1622, 2008.

[8] L. Pastorino and K. P. Lu, "Pathogenic mechanisms in Alzheimer's disease," European Journal of Pharmacology, vol. 545, no. 1, pp. 29-38, 2006.

[9] A. Fukuoka, H. Nakayama, and K. Doi, "Immunohistochemical detection of b-amyloid and $\beta$-amyloid precursor protein in the canine brain and non-neuronal epithelial tissues," Amyloid, vol. 11, no. 3, pp. 173-178, 2004.

[10] M. P. Burns, W. J. Noble, V. Olm et al., "Co-localization of cholesterol, apolipoprotein $\mathrm{E}$ and fibrillar $\mathrm{A} \beta$ in amyloid plaques," Molecular Brain Research, vol. 110, no. 1, pp. 119125, 2003.

[11] T. E. Golde, S. Estus, L. H. Younkin, D. J. Selkoe, and S. G. Younkin, "Processing of the amyloid protein precursor to potentially amyloidogenic derivatives," Science, vol. 255, no. 5045, pp. 728-730, 1992.

[12] C. Haass, E. H. Koo, A. Mellon, A. Y. Hung, and D. J. Selkoe, "Targeting of cell-surface beta-amyloid precursor protein to lysosomes: alternative processing into amyloid-bearing fragments," Nature, vol. 357, no. 6378, pp. 500-503, 1992.

[13] L. M. Refolo, M. A. Pappolla, B. Malester et al., "Hypercholesterolemia accelerates the Alzheimer's amyloid pathology in a transgenic mouse model," Neurobiology of Disease, vol. 7, no. 4, pp. 321-331, 2000.

[14] J. S. Crossgrove, G. J. Li, and W. Zheng, "The choroid plexus removes $\beta$-amyloid from brain cerebrospinal fluid," Experimental Biology and Medicine, vol. 230, no. 10, pp. 771776, 2005.

[15] R. Deane, A. Sagare, K. Hamm et al., "IgG-assisted agedependent clearance of Alzheimer's amyloid beta peptide by the blood-brain barrier neonatal Fc receptor," Journal of Neuroscience, vol. 25, no. 50, pp. 11495-11503, 2005.

[16] T. Thomas, C. McLendon, E. T. Sutton, and G. Thomas, "Cerebrovascular endothelial dysfunction mediated by $\beta$ amyloid,” NeuroReport, vol. 8, no. 6, pp. 1387-1391, 1997.

[17] B. Zlokovic, J. Ghiso, J. Mackic, J. McComb, M. Weiss, and B. Frangione, "Blood-brain barrier transport of circulating Alzheimer's amyloid beta," Biochemical and Biophysical Research Communications, vol. 197, no. 3, pp. 1034-1040, 1993.

[18] G. C. Su, G. W. Arendash, R. N. Kalaria, K. B. Bjugstad, and M. Mullan, "Intravascular infusions of soluble $\beta$-amyloid compromise the blood- brain barrier, activate CNS glial cells and induce peripheral hemorrhage," Brain Research, vol. 818, no. 1, pp. 105-117, 1999.

[19] S. L. Smith, P. K. Andrus, J. R. Zhang, and E. D. Hall, "Direct measurement of hydroxyl radicals, lipid peroxidation, and blood-brain barrier disruption following unilateral cortical 
impact head injury in the rat," Journal of Neurotrauma, vol. 11, no. 4, pp. 393-404, 1994.

[20] S. Galloway, L. Jian, R. Johnsen, S. Chew, and J. C. L. Mamo, " $\beta$-Amyloid or its precursor protein is found in epithelial cells of the small intestine and is stimulated by high-fat feeding," Journal of Nutritional Biochemistry, vol. 18, no. 4, pp. 279-284, 2007.

[21] A. E. Roher, C. L. Esh, T. A. Kokjohn et al., "Amyloid beta peptides in human plasma and tissues and their significance for Alzheimer's disease," Alzheimer's and Dementia, vol. 5, no. 1, pp. 18-29, 2009.

[22] Y. Kuo, M. Emmerling, H. Lampert et al., "High levels of circulating Abeta42 are sequestered by plasma proteins in Alzheimer's disease," Biochemical and Biophysical Research Communications, vol. 257, no. 3, pp. 787-791, 1999.

[23] A. P. James, S. Pal, H. C. Gennat, D. F. Vine, and J. C. L. Mamo, "The incorporation and metabolism of amyloid- $\beta$ into chylomicron-like lipid emulsions," Journal of Alzheimer's Disease, vol. 5, no. 3, pp. 179-188, 2003.

[24] B. L. Burgess, S. A. McIsaac, K. E. Naus et al., "Elevated plasma triglyceride levels precede amyloid deposition in Alzheimer's disease mouse models with abundant A $\beta$ in plasma," Neurobiology of Disease, vol. 24, no. 1, pp. 114-127, 2006.

[25] M. Ujiie, D. L. Dickstein, D. A. Carlow, and W. A. Jefferies, "Blood-brain barrier permeability precedes senile plaque formation in an Alzheimer disease model," Microcirculation, vol. 10, no. 6, pp. 463-470, 2003.

[26] J. C. L. Mamo, L. Jian, A. P. James, L. Flicker, H. Esselmann, and J. Wiltfang, "Plasma lipoprotein $\beta$-amyloid in subjects with Alzheimer's disease or mild cognitive impairment," $A n$ nals of Clinical Biochemistry, vol. 45, no. 4, pp. 395-403, 2008.

[27] Y. Namba, H. Tsuchiya, and K. Ikeda, "Apolipoprotein B immunoreactivity in senile plaque and vascular amyloids and neurofibrillary tangles in the brains of patients with $\mathrm{Alz}$ heimer's disease," Neuroscience Letters, vol. 134, no. 2, pp. 264 266, 1992.

[28] R. Takechi, S. Galloway, M. M. S. Pallebage-Gamarallage et al., "Differential effects of dietary fatty acids on the cerebral distribution of plasma-derived apo B lipoproteins with amyloid-," British Journal of Nutrition, vol. 103, no. 5, pp. 652 $662,2010$.

[29] R. Takechi, S. Galloway, M. M. S. Pallebage-Gamarallage, V. Lam, and J. C. L. Mamo, "Dietary fats, cerebrovasculature integrity and Alzheimer's disease risk," Progress in Lipid Research, vol. 49, no. 2, pp. 159-170, 2010.

[30] N. Morgan, "Fatty acids and beta-cell toxicity," Current Opinion in Clinical Nutrition and Metabolic Care, vol. 12, no. 2, pp. 117-122, 2009.

[31] S. R. Chavali, W. W. Zhong, and R. A. Forse, "Dietary $\alpha$ lenolenic acid increases TNF- $\alpha$, and decreases IL-6, IL-10 in response to LPS: effects of sesamin on the A-5 desaturation of $\omega 6$ and $\omega 3$ fatty acids in mice," Prostaglandins Leukot Essent Fatty Acids, vol. 58, no. 3, pp. 185-191, 1998.

[32] N. M. Jeffery, E. A. Newsholme, and P. C. Calder, "Level of polyunsaturated fatty acids and the n- 6 to $n-3$ polyunsaturated fatty acid ratio in the rat diet alter serum lipid levels and lymphocyte functions," Prostaglandins Leukotrienes and Essential Fatty Acids, vol. 57, no. 2, pp. 149-160, 1997.

[33] L. S. Rallidis, G. Paschos, G. K. Liakos, A. H. Velissaridou, G. Anastasiadis, and A. Zampelas, "Dietary alpha-linolenic acid decreases C-reactive protein, serum amyloid A and interleukin-6 in dyslipidaemic patients," Atherosclerosis, vol. 167, no. 2, pp. 237-242, 2003.
[34] B. T. Hawkins and T. P. Davis, "The blood-brain barrier/neurovascular unit in health and disease," Pharmacological Reviews, vol. 57, no. 2, pp. 173-185, 2005.

[35] S. Galloway, R. Takechi, M. M. S. Pallebage-Gamarallage, S. S. Dhaliwal, and J. C. L. Mamo, "Amyloid-beta colocalizes with apolipoprotein B in absorptive cells of the small intestine," Lipids in Health and Disease, vol. 8, no. 1, article 46, 2009.

[36] C. K. Roberts, R. J. Barnard, K. H. Liang, and N. D. Vaziri, "Effect of diet on adipose tissue and skeletal muscle VLDL receptor and LPL: implications for obesity and hyperlipidemia," Atherosclerosis, vol. 161, no. 1, pp. 133-141, 2002.

[37] K. C. Hayes, P. Khosla, T. Hajri, and A. Pronczuk, "Saturated fatty acids and LDL receptor modulation in humans and monkeys," Prostaglandins Leukotrienes and Essential Fatty Acids, vol. 57, no. 4-5, pp. 411-418, 1997.

[38] Y. Park, P. G. Jones, and W. S. Harris, "Triacylglycerol-rich lipoprotein margination: a potential surrogate for wholebody lipoprotein lipase activity and effects of eicosapentaenoic and docosahexaenoic acids," American Journal of Clinical Nutrition, vol. 80, no. 1, pp. 45-50, 2004.

[39] Y. Park and W. S. Harris, "Omega-3 fatty acid supplementation accelerates chylomicron triglyceride clearance," Journal of Lipid Research, vol. 44, no. 3, pp. 455-463, 2003.

[40] L. Eiselein, D. W. Wilson, M. W. Lamé, and J. C. Rutledge, "Lipolysis products from triglyceride-rich lipoproteins increase endothelial permeability, perturb zonula occludens1 and F-actin, and induce apoptosis," American Journal of Physiology, vol. 292, no. 6, pp. H2745-H2753, 2007.

[41] K. C. Maki, M. E. Van Elswyk, D. McCarthy et al., "Lipid responses in mildly hypertriglyceridemic men and women to consumption of docosahexaenoic acid-enriched eggs," International Journal for Vitamin and Nutrition Research, vol. 73, no. 5, pp. 357-368, 2003.

[42] N. D. Riediger, R. Othman, E. Fitz, G. N. Pierce, M. Suh, and M. H. Moghadasian, "Low n-6:n-3 fatty acid ratio, with fish- or flaxseed oil, in a high fat diet improves plasma lipids and beneficially alters tissue fatty acid composition in mice," European Journal of Nutrition, vol. 47, no. 3, pp. 153-160, 2008.

[43] L. Calabresi, B. Villa, M. Canavesi et al., "An omega-3 polyunsaturated fatty acid concentrate increases plasma high-density lipoprotein 2 cholesterol and paraoxonase levels in patients with familial combined hyperlipidemia," Metabolismml, vol. 53, no. 2, pp. 153-158, 2004.

[44] E. A. Almeida, R. A. Morales, and M. R. Ozaki, "Endothelial dysfunction, lipid peroxidation and cholesterol level in rabbit arteries: relationship to progressive hypercholesterolemia," Clinica e Investigacion en Arteriosclerosis, vol. 19, no. 6, pp. 293-299, 2007.

[45] B. Hennig, M. Toborek, and C. J. McClain, "High-energy diets, fatty acids and endothelial cell function: implications for atherosclerosis," Journal of the American College of Nutrition, vol. 20, no. 2, pp. 97-105, 2001.

[46] P. M. Yao and I. Tabas, "Free cholesterol loading of macrophages is associated with widespread mitochondrial dysfunction and activation of the mitochondrial apoptosis pathway," Journal of Biological Chemistry, vol. 276, no. 45, pp. 4246842476, 2001.

[47] S. K. Peng, P. Tham, C. B. Taylor, and B. Mikkelson, "Cytotoxicity of oxidation derivatives of cholesterol on cultured aortic smooth muscle cells and their effect on cholesterol biosynthesis," American Journal of Clinical Nutrition, vol. 32, no. 5, pp. 1033-1042, 1979. 
[48] Y. T. Kuo, P. W. So, J. R. Parkinson et al., “The combined effects on neuronal activation and blood-brain barrier permeability of time and n-3 polyunsaturated fatty acids in mice, as measured in vivo using MEMRI," NeuroImage, vol. 50, no. 4, pp. 1384-1391, 2010.

[49] A. Garrido, M. Garate, R. Campos, A. Villa, S. Nieto, and A. Valenzuela, "Increased susceptibility of cellular membranes to the induction of oxidative stress after ingestion of high doses of fish oil: effect of aging and protective action of dl-a tocopherol supplementation," Journal of Nutritional Biochemistry, vol. 4, no. 2, pp. 118-122, 1993.

[50] A. Garrido, F. Garrido, R. Guerra, and A. Valenzuela, "Ingestion of high doses of fish oil increases the susceptibility of cellular membranes to the induction of oxidative stress," Lipids, vol. 24, no. 9, pp. 833-835, 1989.

[51] K. Kikugawa, Y. Yasuhara, K. Ando, K. Koyama, K. Hiramoto, and M. Suzuki, "Effect of supplementation of n-3 polyunsaturated fatty acids on oxidative stress-induced DNA damage of rat hepatocytes," Biological and Pharmaceutical Bulletin, vol. 26, no. 9, pp. 1239-1244, 2003.

[52] M. Artwohl, A. Lindenmair, V. Sexl et al., "Different mechanisms of saturated versus polyunsaturated FFA-induced apoptosis in human endothelial cells," Journal of Lipid Research, vol. 49, no. 12, pp. 2627-2640, 2008.

[53] D. A. Healy, R. W. G. Watson, and P. Newsholme, "Polyunsaturated and monounsaturated fatty acids increase neutral lipid accumulation, caspase activation and apoptosis in a neutrophil-like, differentiated hl-60 cell line," Clinical Science, vol. 104, no. 2, pp. 171-179, 2003. 


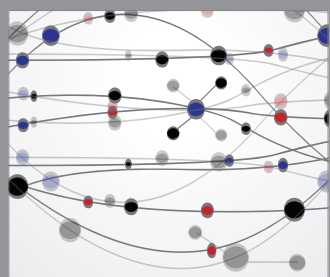

The Scientific World Journal
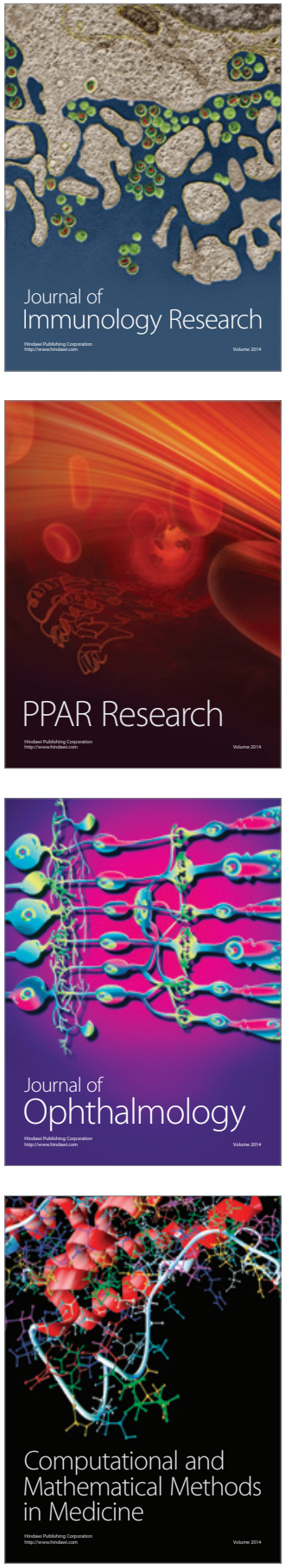

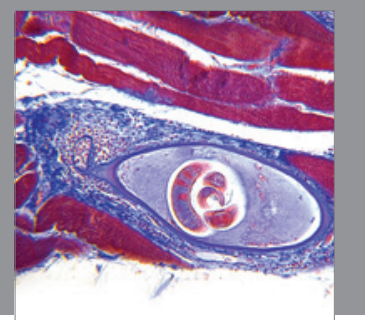

Gastroenterology

Research and Practice
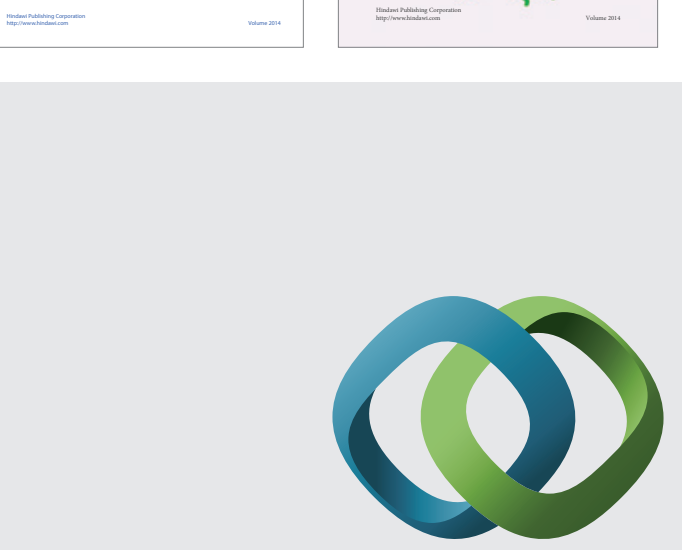

\section{Hindawi}

Submit your manuscripts at

http://www.hindawi.com
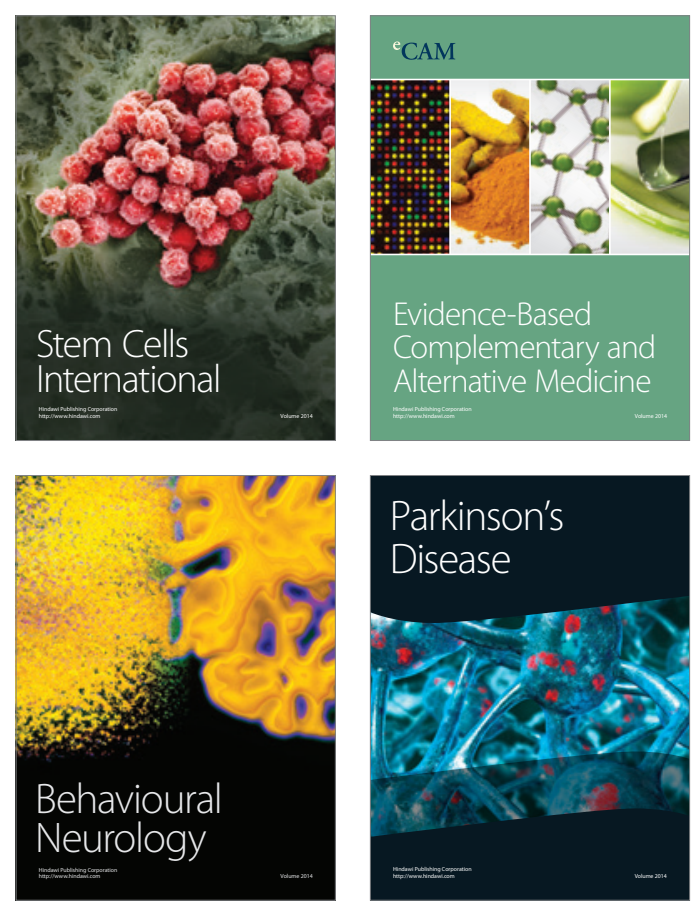

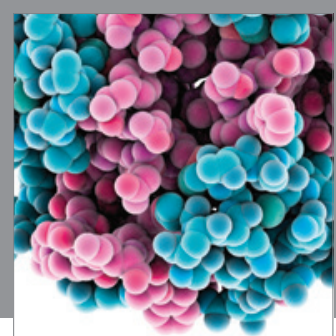

Journal of
Diabetes Research

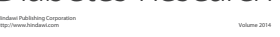

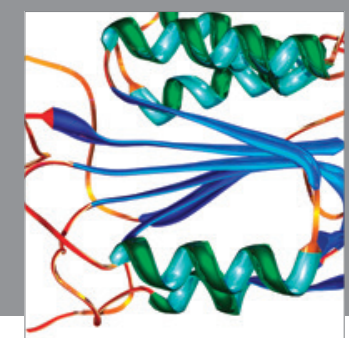

Disease Markers
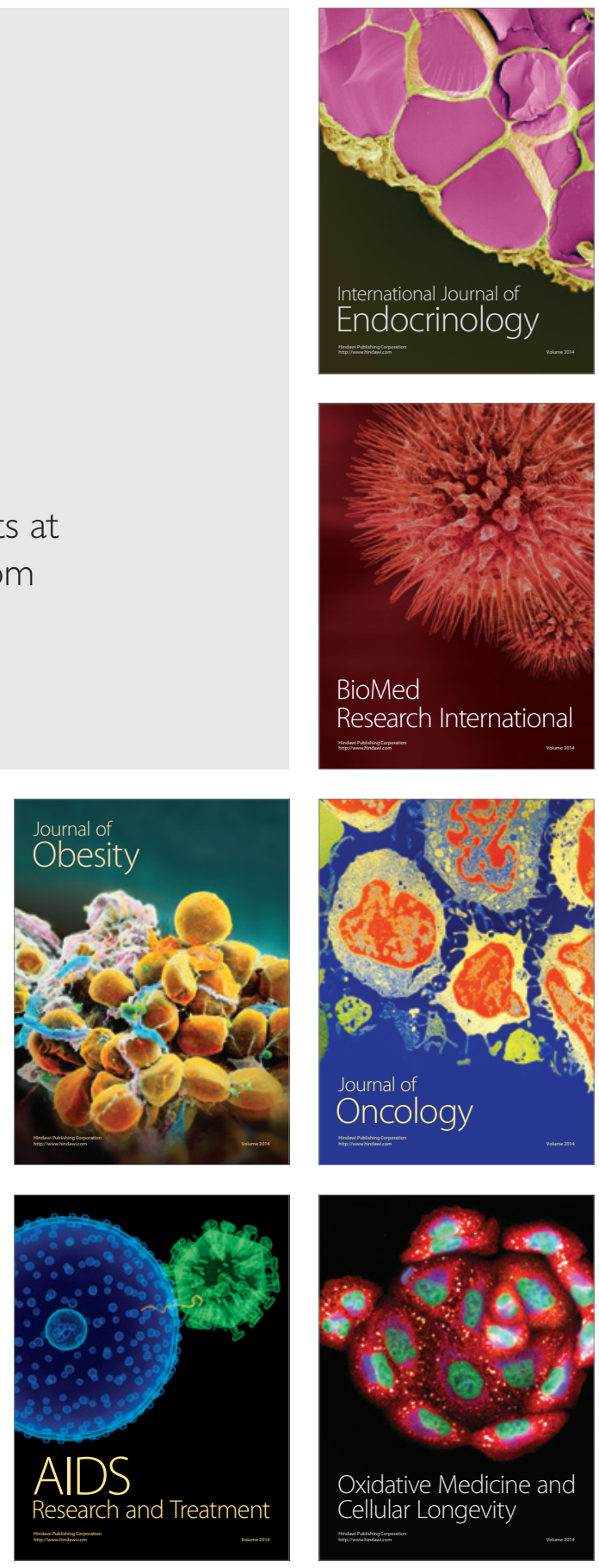